\section{FORMAÇÃO DE PROFESSORES EM EDUCAÇÃO FÍSICA E A EDUCAÇÃO DE JOVENS E ADULTOS}

\author{
PHYSICAL EDUCATION TEACHER TRAINING AND YOUTH AND ADULT \\ EDUCATION
}

\section{FORMACIÓN DE PROFESORES EN EDUCACIÓN FÍSICA Y EDUCACIÓN DE JÓVENES Y ADULTOS}

\section{Rosa Malena de Araújo Carvalho*, Maria Cecília da Silva Camargo*}

Palavras chave: Educação Física. Educação continuada. Docentes. Universidades.

Resumo: 0 artigo objetiva compartilhar estudos referentes à formação inicial de professores e professoras de Educação Física para atuação na Educação de Jovens e Adultos (EJA), através de ações acadêmicas desenvolvidas em duas universidades públicas federais. A discussão apresentada se origina das pesquisas dessas realidades que, a partir de distintas bases empíricas, considerando a educação de jovens e adultos como direito e devir e apoiadas em visão crítica da Educação Física, analisam esse fenômeno em dois recortes espaciais, no Sul e no Sudeste do Brasil. Nas considerações, aponta a importância e a responsabilidade das universidades para a concretização dessa prática pedagógica em uma modalidade que é expressão das desigualdades sociais e, complementarmente a isso, o necessário compromisso com uma formação de professores de Educação Física atenta às especificidades da EJA.

\section{Keywords:} Physical Education. Education, Continuing. Faculty. Universities.

Abstract: The article aims to share studies about initial training of Physical Education teachers to work with youth and adult education, through academic actions developed in two Federal Universities. The discussion originates from studies on these realities that, based on distinct empirical foundations and considering the education of youth and adults as a right and becoming, based on a critical view of Physical Education, analyze this phenomenon in two spaces - Brazil's South and Southeast regions. The considerations point out Universities' importance and responsibility for making this pedagogical practice come through in a way that expresses social inequalities. The necessary commitment to training of Physical Education teachers that takes into account the specificities of youth and adult education complements that.

Palabras clave: Educación Física.

Resumen: El artículo tiene por objetivo compartir estudios referentes a la formación inicial de profesores y profesoras de Educación Física para ejercer en la Educación de Jóvenes Educación continua. y Adultos, a través de acciones académicas desarrolladas en dos Universidades Públicas Docentes. Universidades.
Federales. La discusión presentada se origina en investigaciones sobre esas realidades que, desde distintas bases empíricas y considerando la educación de jóvenes y adultos como derecho y devenir y, apoyadas en una visión crítica de la Educación Física, analizan ese fenómeno en dos recortes espaciales: en el sur y en el sudeste de Brasil. En las consideraciones, se apunta la importancia y la responsabilidad de las Universidades para la concreción de esa práctica pedagógica en una modalidad que es expresión de las desigualdades sociales y, complementario a ello, el necesario compromiso con una formación de profesores de Educación Física atenta a las especificidades de la Educación de Jóvenes y Adultos.
*Universidade Federal Fluminense (UFF). Rio de Janeiro, RJ, Brasil. E-mail: rosamalena@id.uff.br

**Universidade Federal de Santa Maria (UFSM). Santa Maria, RS, Brasil. E-mail: mceciliacg6@ hotmail.com

Recebido em: 27-07-2018 Aprovado em: 17-04-2019 Publicado em: 14-05-2019

DOI: https://doi.org/10.22456/1982-8918.85233 (c) (1) ()? Licence 


\section{INTRODUÇÃOO}

As autoras deste artigo fazem parte do campo da Educação Física (EF), com produções próprias que integram o grupo de autores que a caracterizam, na escola, como prática pedagógica em que corpo e práticas corporais expressam multiplicidade, diferença, particularidade - e não sentido único, absoluto, universal. Isso significa que nossa capacidade de singularização requer vinculações dinâmicas com os contextos, olhando com aproximação e estranhamento a realidade que nos forma e que por nós é formada. Assim, nossas histórias profissionais estão afetadas pelas formas de dialogar com as intensidades das nossas relações.

Sem perder de vista as urgências do cenário brasileiro na orientação e desenvolvimento do trabalho acadêmico realizado, o estudo aqui apresentado contém resultados de pesquisas que marcam os cotidianos de duas professoras inseridas em universidades públicas federais, de diferentes regiões do Brasil (Sul e Sudeste), formadoras de professores e professoras de EF para a educação básica, especialmente para as escolas públicas. As questões compartilhadas relacionam-se com esse universo que envolve ensino, pesquisa e extensão na formação inicial e continuada de professores, na perspectiva do fortalecimento da universidade e da escola pública como espaços de encontros, criações e transformações.

Para nós, trazer dois espaços formadores possibilita a experiência do contraste, a percepção de pistas para elaborar a partir das diferenças, sem desconsiderar as semelhanças. 0 que ajuda a indagar o realizado, inventar novos sentidos e significados, no movimento de aguçar processos que afirmem a educação como direito, o saber socialmente produzido como patrimônio de todos e todas. Nesse caminhar, nossos estudos objetivam problematizar o contexto dessa formação para a Educação de Jovens e Adultos (EJA), colaborando com a qualificação da formação inicial e continuada de professores e professoras de EF e, ao mesmo tempo, com a urgência de reconhecer e preparar professores para uma modalidade que expõe a perversidade das relações desiguais da vida em sociedade (BRASIL, 2000).

Nosso quadro teórico se fundamenta em perspectivas críticas da educação e, do mesmo modo, da EF. No campo da EJA, assumimos uma configuração que reúne conceitos e posições inspiradas em Paulo Freire, Jane Paiva, Leôncio Soares e outros pesquisadores envolvidos com os debates e Fóruns Nacionais da EJA, assim como nas Diretrizes Curriculares Nacionais para a EJA (BRASIL, 2000), os quais auxiliam a afirmar a EJA como expressão do direito à educação. Já no campo da EF, tomamos como referência as perspectivas críticas que nos proporcionam pensar essa prática pedagógica em diálogo com a realidade da EJA.

Ao usarmos perspectivas críticas, sem especificar as abordagens crítico-superadora e crítico-emancipatória, ambas reconhecidas no campo da EF, o fazemos intencionalmente. Entendemos que entre as abordagens citadas existam distinções em suas fundamentações, mas, por outro lado, apostamos nas possibilidades de aproximações que possam fortalecer um pensamento crítico mais abrangente e que responda às muitas especificidades da EJA. Explicitamos, então, que essas perspectivas guiam nossos trabalhos, aparecem em muitas situações de inserção na EJA, mas aqui não as poremos em discussão, pois nosso maior objetivo é aprofundar a compreensão da modalidade e quais as questões urgentes e emergentes que necessitam de nossas pesquisas e proposições na EF que acontece na EJA.

No campo da EF, concordando com Souza Júnior et al. (2017) e Carvalho (2017b;2017c), existem dois problemas centrais na discussão crítica: desnaturalizar o que caracterizamos 
como corpo; e sair da característica esportiva que as práticas corporais hegemonicamente recebem. Nossa problematização e inquietação constituem-se pela baixa inserção da área na modalidade; como identificamos a presença da EJA nas licenciaturas para a EF; e como essa prática pedagógica vem sendo desenvolvida nas instituições escolares. Em nossa delimitação do objeto de estudo, trazemos o realizado na formação de professores e professoras de EF para a Educação de Jovens e Adultos (EJA).

Ao adotarmos a abordagem metodológica qualitativa, delineamos nossas pesquisas (BARBIER. 2007; MINAYO, 2014) por uma escrita como experiência', a qual não se apresenta como verdade, mas como atenção e indagação do realizado, em que as fontes bibliográficas dialogam com o universo formador vivenciado. Temos indagado nossas bases empíricas, por meio de profícuo diálogo e encontros, em diferentes situações acadêmicas, como integrar painel no Encontro Nacional de Didática e Prática de Ensino (ENDIPE), em 2014; intercâmbio na UFSM (novembro de 2016); livro em coautoria (em 2017 e outro em andamento); encontros no Congresso Brasileiro de Ciências do Esporte (CONBRACE). Essas situações vêm alimentando um trabalho colaborativo de pesquisa, inspirado em pressupostos de Ibiapina (2008) que nos tem levado a um processo reflexivo por meio da imersão no conhecimento teórico em diálogo com o mundo da experiência, resultando, inclusive, neste artigo.

Nesta introdução, indicamos as bases que sustentam as pesquisas que colocam a EJA como modalidade da educação básica em evidência e a decisão metodológica. Nas duas próximas seções do artigo, traremos dados, resultados do que pesquisamos na formação das instituições em que estamos inseridas (regiões Sul e Sudeste do país) e nas duas últimas partes, com algumas discussões e considerações, desejando impactar nossas realidades específicas (institucionais) e coletivas (políticas públicas; paradigmas) de trabalho.

\section{EDUCAÇÃO DE JOVENS E ADULTOS NO SUL DO PAÍS - INDAGANDO UMA TRAJETÓRIA INSTITUCIONAL}

A EJA não é pauta frequente nos currículos de formação de professores. No entanto, a existência de uma disciplina de Docência Orientada em EF, na matriz curricular do curso pesquisado, de caráter obrigatório e oferecida no sétimo período, possibilitou que esse tema fosse inserido no percurso formativo dos(as) futuros(as) professores(as).

Ao assumir a referida disciplina no ano de 2010, dando prosseguimento à prática de outros docentes, os(as) estudantes foram orientados em uma prática docente de EF junto a turmas de EJA em escolas das redes estadual e municipal na cidade do sul do país. Diríamos que, ao longo dos dois primeiros semestres, tivemos a oportunidade de fazer uma aproximação à realidade da EJA nas escolas públicas da região, que foi complementada por um projeto de pesquisa igualmente voltado ao ensino da EF nessa modalidade da educação.

A combinação de docência e pesquisa foi de extrema importância para que a disciplina citada começasse a ganhar uma identidade que ao longo dos últimos anos vem se consolidando como um espaço-tempo que expressa uma luta, quase uma resistência em relação a um segmento da educação pública pouco visível no campo da EF. Essa condição

\footnotetext{
1 "....] falar desde a experiência e para a experiência consiste, exclusivamente, em dizer algo a alguém, como igual, e não como aluno, não como alguém que há de the explicar alguma coisa ou convencer-lhe de alguma coisa" [tradução nossa] (LARROSA, J. Herido de realidade y em busca de realidade. Notas sobre los lenguajes de la experiencia. In: CONTRERAS DOMINGO, José; FERRÉR, Nuria. (Comps). Investigar la experiencia educativa. Madrid: Ediciones Morata, 2010. p. 87-116, citação retirada da p. 115).
} 
inclui tanto os currículos das licenciaturas quanto as produções científicas, salvo raras exceções.

Em pesquisa envolvendo cursos de licenciatura em EF de universidades públicas e privadas no estado do Rio Grande do Sul, Silva (2013) constatou que, entre dez cursos consultados, apenas quatro deles apresentam disciplinas relacionadas à EJA, sendo que em apenas um dos casos essa modalidade da educação é tema central da disciplina e em caráter obrigatório. Nos outros casos, foram encontradas disciplinas optativas nas quais a EJA era tema central ou, em disciplina obrigatória, o ensino da EF é tematizado no ensino médio e EJA. Em alguns casos, o estágio supervisionado pode ser realizado nessa modalidade de ensino, podendo, em um dos cursos consultados, haver uma indução do curso para que os estudantes realizem o Estágio de Ensino Fundamental II em turmas de EJA.

Os dados acima expõem a marginalidade da EJA no processo formativo de professores de EF e, consequência disso, o despreparo dos(as) futuros(as) professores(as) para atuarem com essa modalidade da educação. Esse cenário parece reproduzir a lógica da "formação pelas bordas" - conforme Arroyo (2012) -, ao afirmar que o(a) educador(a) de EJA é formado(a) no cotidiano.

Ao acompanhar os(as) estudantes nas suas práticas docentes nas escolas, constatamos que os(as) professores(as) de EF que atuam com EJA não se preparam formalmente para as especificidades dessa modalidade da educação. Constituem-se professores de EJA imersos na docência e ora reproduzem práticas usadas em outros espaços pedagógicos (no ensino fundamental ou médio regular), ora elaboram novas práticas, na medida em que se dão conta da realidade que essa modalidade encerra. Essa afirmação, que sintetiza percepções acumuladas na condição de formadora, é corroborada por um estudo (SILVA, GÜNTHER, 2011; SILVA, 2013) que destaca a centralidade dos conhecimentos elaborados no cotidiano da docência frente às turmas de EJA. As autoras desse estudo acrescentam que, para alguns professores, a atuação na EJA representa um reinício na trajetória docente, considerando-se 0 desconhecimento dessa realidade e a necessidade de formular novos conhecimentos para responder a isso.

Na mesma direção, Laffin (2012) destaca alguns aspectos que emergiram de um estudo sobre a construção da docência na EJA, incluindo a condição permanente de um "vir a ser", combinada à intencionalidade de exercer uma docência coerente com as especificidades dessa modalidade da educação. A mesma autora sinaliza para o processo de tomada de consciência que acompanha muitos professores que, ao longo de sua trajetória, assumem uma posição de comprometimento com a EJA, a partir de tensões e contradições próprias da modalidade e que os leva a uma recusa a uma docência fundada na mera adaptação dos conteúdos do ensino regular para turmas de jovens e adultos e, em oposição a isso, formular uma educação com estatuto próprio, adequado às condições e necessidades de seu público.

Amorim e Duques (2017) ratificam o problema, corroborando a reivindicação de que a EJA seja melhor atendida por políticas públicas de educação, particularmente no que diz respeito à formação de professores(as), sublinhando o desejo de educadores de se qualificarem para atuar com essa modalidade da educação.

O exercício da pesquisa e da docência tem ensinado que formar professores para atuar com a EJA exige um olhar atento e sensível para os(as) educandos(as) que a integram, pela 
presença concreta, no dia a dia das escolas. Mais do que isso, é necessário um olhar para o ensino fundamental de nove anos, cujas fragilidades têm gerado um contingente de crianças e adolescentes que, ao longo da escolarização, "ficam pelo caminho" e irão compor as turmas de EJA.

Mello (2009) captou esse processo com grande sensibilidade e o traduziu muito bem. O autor problematiza a crescente presença de adolescentes nas turmas de EJA e as diferentes reações de educadores(as) diante disso, colocando à mostra um cotidiano perverso que vem marcando a escolarização de estudantes, mediante uma situação de multirrepetência, indisciplina e em condição próxima de evasão escolar. Nas palavras do autor, o encaminhamento para a EJA tem sido a "saída salomônica" e, por outro lado, sido motivo de preocupação e intensos debates sobre a idade limite para ingresso na modalidade.

Os argumentos de Mello auxiliam a interpretar o que encontramos nas escolas quando os licenciandos iniciam suas práticas docentes com turmas de EJA. Passada a perplexidade inicial, emerge a necessidade de repensar formas de docência (ainda em construção), diante de situações desafiadoras e, por vezes, desconcertantes, de turmas nas quais a EF é tratada como uma "atividade opcional", "hora do futebol", "momento de descontrair e socializar". Em contraponto, em algumas escolas, encontramos professores capazes de mobilizar suas turmas e delinear um componente curricular, dotado de conhecimentos próprios, contemplando as especificidades do público da EJA.

Ao longo de sete anos, construímos uma aproximação com algumas escolas e acompanhado mudanças no que tange à EF. Se por um lado não logramos êxito em um vínculo formal para ações mais contínuas junto às escolas, por outro lado, as parecerias com algumas escolas e, mais especificamente, com alguns professores de EF, têm resultado em experiências significativas para a formação de futuros(as) professores(as).

A partir de um estudo realizado em 2012 com integrantes da disciplina, foi possível constatar que muitos acadêmicos desconhecem a realidade da EJA e surpreendem-se com a presença, cada vez maior, de adolescentes nas turmas nas quais atuam. Comum a todos que integraram o estudo foi o relato de uma situação marginal da EF no currículo das escolas onde desenvolveram a prática docente, com um caráter recreativo e opcional.

Posterior a isso, em 2013, foi possível a realização de um projeto de pesquisa/extensão com a presença de um estudante de EF atuando em conjunto com a professora responsável pela EF. Nessa experiência foi possível a inserção de diferentes práticas corporais que incluíam jogos, ginástica, caminhadas, partindo da problematização com a turma sobre o que seria conteúdo da EF. O processo permitiu a desconstrução de algumas representações sobre a EF por parte dos estudantes da EJA e apresentação de práticas que pudessem subsidiar novas formas de compreender esse componente curricular.

Outro aspecto que merece ser mencionado é a troca de professores de EF ocorrida em algumas escolas, ao longo do período em que temos trabalhado com essa disciplina. Tal fato exige uma análise mais cuidadosa, pois, em algumas situações, representou mudanças relevantes nas aulas e que vêm resultando em uma compreensão diferenciada sobre esse componente curricular.

Em uma das escolas onde isso ocorreu, o ingresso de um novo professor abriu perspectivas para a EF, pois ele iniciou uma sistematização de conteúdos a serem trabalhados 
ao longo das turmas de EJA/ensino médio, de modo a assegurar a tematização dos jogos, esportes, lutas e conhecimentos sobre o corpo. Essa mesma escola apresentava uma proporção elevada de estudantes que não participavam das aulas de EF, alegando alguma das condições previstas legalmente ${ }^{2}$, situação que foi revertida com as práticas pedagógicas implementadas desde então.

Fato similar ocorreu em outra escola na qual a professora ingressante encontrou um quadro de baixa participação nas aulas e uma rotina de aulas reduzida ao oferecimento de jogos de tabuleiro. Também nesse contexto, diferentes práticas corporais passaram a ser apresentadas nas aulas, contando com uma postura de intenso engajamento por parte da professora, resultando em um aumento expressivo de participação dos estudantes, que tem se mantido ao longo dos últimos anos.

Essas mudanças têm impactado de modo considerável os(as) acadêmicos(as) que se inserem nessa escola para a realização da prática docente com turmas de EJA. Tanto o professor quanto a professora citados acima já participaram de rodas de conversa com algumas turmas e têm exercido um papel importante de coformadores junto às duplas de acadêmicos(as) que têm realizado sua prática docente com turmas sob a regência de algum deles. Em certa medida, algumas mudanças se iniciaram a partir de momentos de trocas entre os(as) professores(as) e os(as) licenciandos(as) ao longo das aulas nas quais estes realizam a atividade de docência orientada prevista na disciplina. Outro momento relevante para desencadear algumas reflexões são as visitas de observação quando, muitas vezes, partimos de situações concretas vivenciadas pelos(as) licenciandos(as) que se mostram fecundas para alimentar questionamentos e discussões que têm sua continuidade nas aulas do curso, ao serem compartilhadas com toda a turma. Por meio da relação com a disciplina mencionada temos observado que os(as) professores(as) que atuam com EJA vão construindo e, por vezes, reconstruindo suas práticas, na medida em que exercem a docência e convivem com a realidade dessa modalidade da educação.

Outras observações desses estudos e experiências que têm se destacado ao longo dos últimos anos nos levam a considerar que a relação que se estabelece diretamente com o(a) professor(a) é bastante relevante. Alguns(mas) professores(as) sentem-se reconhecidos(as) e apoiados(as) com a presença dos(as) acadêmicos(as) e com nossas visitas à escola, demonstrando interesse em reelaborar suas práticas pedagógicas e superar dificuldades presentes. É preciso lembrar que esses(as) professores(as) que atuam com EJA não tiveram formação específica para isso e atuam com outros níveis de ensino, fato a ser considerado, conforme alertam Jardilino (2014), Amorim e Duques (2017).

Pensar o trabalho pedagógico na EJA exige, segundo Soares (2011), o reconhecimento das especificidades do público que a constitui. $O$ autor inclui a formação inicial entre os aspectos a serem considerados, mas nos parece que a formação inicial é, ou pode ser, parte de um processo de formação continuada no qual professores que estão na escola possam assumir 0 lugar de coformadores, mas também repensar suas próprias práticas, a partir das provocações levadas pelos estudantes.

2 No art. 26 da Lei de Diretrizes e Bases da Educação Nacional (2018), o parágrafo 3ํㅡㄹ menciona situações que facultam a prática nas aulas de EF mediante algumas condições que atingem diretamente o público da EJA. 


\section{A FORMAÇÃO PARA A EJA NO SUDESTE DO PAÍS - CONSTRUINDO E PROBLEMATIZANDO UMA REALIZAÇÃO INSTITUCIONAL}

A inserção da formação inicial e continuada para a EJA, aqui colocada em discussão, faz parte de um trabalho institucional que contém uma jovem licenciatura em EF (iniciada em 2007), cujos docentes participam de diferentes ações acadêmicas voltadas à qualificação profissional e valorização da educação básica no espaço público, com atuação em diferentes projetos, incluindo Curso de Extensão para professores com atuação na EJA e Curso de Especialização em EF Escolar (esse desde 1991).

Ao apresentar resultados de pesquisas relacionadas à experiência em construção, nesse contexto, com a formação para a modalidade EJA, destacamos que, das universidades públicas federais localizadas no estado do Rio de Janeiro, encontramos a graduação em EF na Universidade Federal Fluminense (UFF), na Universidade Federal do Rio de Janeiro (UFRJ) e na Universidade Federal Rural do Rio de Janeiro (UFRRJ). Na Universidade Federal do Estado do Rio de Janeiro (UNIRIO) ainda não há formação para essa licenciatura. Visitando as páginas dessas instituições ${ }^{3}$, para identificar o currículo realizado nessas licenciaturas, apenas a realizada pela UFRRJ aparece que o "Estágio Supervisionado III" (7ํperíodo), com 100h, pode ocorrer no ensino médio e/ou EJA, e na UFF encontramos a disciplina optativa "EF Escolar e EJA".

No processo institucional aqui delimitado, marcado pelo princípio da indissociabilidade entre ensino, pesquisa e extensão, as diferentes ações acadêmicas relacionadas à EJA começaram através de projetos de extensão - como é característica marcante da universidade iniciar a formação para a modalidade (SOARES, 2008). Em 2011-surge o primeiro projeto de extensão associado à EJA (Curso de Extensão para professores com atuação na EJA) e, em 2012, o segundo projeto de extensão (CirandEJAs); assim como surgem projetos de iniciação à docência (monitorias em diferentes elementos curriculares e no PIBID) e projetos de pesquisa (trabalhos de conclusão de curso e pesquisas com bolsa FAPERJ e PIBIC) abordando a EJA.

Esse conjunto de ações permitiu que muitos graduandos e professores universitários conhecessem essa realidade, percebessem a modalidade - o que foi, paulatinamente, criando condições para a execução, a partir de 2017, da disciplina "EF escolar e EJA", em forma optativa, na graduação em EF. Disciplina aprovada, pelo colegiado do Curso, desde 2010. Entramos no quarto semestre de execução dessa disciplina e uma avaliação inicial, qualitativa, do trabalho realizado vem destacando a responsabilidade das universidades em relação às dificuldades e aos avanços da EF na EJA. Os projetos já sinalizavam o quanto os(as) graduandos(as) em EF, que tiveram contato com a modalidade e realizaram trabalho de conclusão de curso (TCC), destacam a importância da formação inicial para a EJA4. As ações de ensino, pesquisa e extensão vinculadas à EJA, portanto, vêm problematizando as práticas corporais, aproximando-as do contexto histórico-social em que essa modalidade aparece; destacando a educação pela diferença, indagando, assim, os processos educacionais e sociais predominantes - que historicamente vêm excluindo a camada social que constitui essa modalidade, como apontam as Diretrizes Nacionais Curriculares para a EJA (BRASIL, 2000). O que colabora com um trabalho institucional que privilegie a formação profissional para

\footnotetext{
3 Disponível em: http://educacaofisica.sites.uff.br/; https://www.eefd.ufrj.br/; http://cursos.ufrrj.br/grad/educacaofisica/departamento-deeducacao-fisica-e-desporto/ Acesso em 24 jul.2017. 
a docência, com uma atuação questionadora dos significados hegemônicos atribuídos à EF e à sociedade e que identifique/crie/fortaleça os sentidos que modificam esse quadro.

Nessa perspectiva, tomando como objeto de estudos as experiências corporais na formação docente e como isso é exercido na educação básica, especialmente na EJA, reconhecendo as práticas corporais como conhecimento, linguagem e patrimônio humano (SOARES, et al. 2014), somos convidados a pensar quais exercícios de educação, escola e sociedade cotidianamente criamos, com nossa ação docente.

Quais experiências corporais circulam nas escolas? Como são inseridas nos processos escolares pelo exercício da docência? Quais as relações dessas práticas corporais com outras questões que constituem a vida em sociedade? No movimento de construir respostas a essas e outras questões, percorremos o caminho de aprofundar e ampliar um trabalho docente que vem questionando as ideias hegemônicas de corpo, experiência, conhecimento, educação e sociedade, entendendo que isso significa olhar o mundo e as urgências que busquem a afirmação da vida (ARENDT,1996; SLOTERDIJK, 2000; CARVALHO, 2017b).

Nesse processo, reconhecemos a importância social da escolarização diante das desigualdades em que grande parte da população brasileira se encontra. Como exemplo, a PNAD (Pesquisa Nacional por Amostra de Domicílios), realizada em 2014 pelo IBGE (Instituto Brasileiro de Geografia e Estatística) e divulgada em 2015, traz o dado de que 8,3\% da população brasileira é analfabeta absoluta - o que significa pouco mais de 13 milhões de habitantes, em um universo de 203 milhões brasileiros.

Ao questionarmos esses dados em pleno século XXI, também identificamos que na formação de professores(as) a educação de adultos pouco aparece. Com exceção da Pedagogia, é uma discussão pouco existente (ou inexistente) nas demais formações de professores. Junto com isso, na iniciação à docência, o(a) professor(a) recém-formado(a) pode ser alocado(a) nessas turmas, com sua inserção não possuindo formação ou acompanhamento inicial. 0 que significa que esses professores, ao exercerem atuação nessa modalidade da educação, colocam em atuação o que mais está impregnado em suas formações. O que requer formação continuada para entender essa realidade e as demandas desses alunos, na criação de práticas pedagógicas direcionadas a eles (ARROYO, 2012). Mas o que exercita, em sua formação inicial, que lhe possibilite desenvolver a docência em benefício do aluno e do objeto de estudos que os unem?

Identificamos que isso nos coloca diante do desafio de eleger quais conhecimentos deveriam estar na formação inicial e como abordá-los (BARBOSA-RINALDI, 2008) - indagações que vêm orientando os projetos anteriormente apresentados. Após ajuste curricular discutido no final de 2017, a disciplina "EF Escolar e EJA" passará a ser oferecida em forma obrigatória, no sétimo período da licenciatura em EF. A ementa aprovada traz a EJA na atualidade brasileira (perspectivas históricas - educação popular e legislação); as relações entre EJA e o trabalho pedagógico; questões teórico-metodológicas da EF Escolar e a EJA; os conteúdos da EF Escolar e os sujeitos da EJA (incluindo os jovens em cumprimento de medidas socioeducativas) - favorecendo a compreensão de juventude, intergeracionalidade e o adulto idoso. Após o ajuste curricular, dedicará dez horas de sua carga horária para atividades de prática como componente curricular (PCC), consolidadas através de visitas a unidades escolares de educação básica dos municípios de Niterói e seu entorno. Como objetivos da disciplina, espera-se que os(as) graduandos(as) identifiquem a constituição da EJA no Brasil; caracterizem a formação do(a) 
professor(a) frente às especificidades desse alunado; reconheçam a intergeracionalidade como potencializadora do processo dos diferentes sujeitos que compõem o alunado dessa modalidade; caracterizem as relações entre EF e o desenvolvido na EJA; visitem espaços educativos com EF na EJA; produzam materiais, oficinas, encontros que potencializem a EF na modalidade.

O desenvolvimento e os questionamentos desses projetos de formação inicial e continuada têm revelado o quanto estudar a EJA gera deslocamentos em relação à escolarização de maneira geral, provocando novas indagações relacionadas à EF como prática pedagógica, assim como a organização do trabalho docente necessário para a inserção na modalidade.

\section{BREVE DISCUSSÃO}

A partir das experiências pesquisadas, considerando o contexto e os processos institucionais anteriormente mencionadas, o resultado deste estudo conjunto nos suscita considerações de diversas naturezas, as quais passamos a apresentar.

As situações aqui narradas nos autorizam a afirmar o quanto essas ações direcionadas à docência favorecem a dinâmica de um trabalho nosso e das instituições em que estamos inseridas, de modo a priorizar o fortalecimento da profissão professor/professora junto à EJA. Para tanto, é pertinente ampliar as experiências acadêmicas dos(as) graduandos(as); favorecer a vinculação permanente entre espaços formadores na própria universidade, entre situações universitárias distintas, entre a educação básica e o ensino superior; e avaliar os impactos sociais dessa formação, assegurando a presença da EJA na pauta das licenciaturas de EF.

Já na formação continuada (seja presencialmente, através das ações nas universidades ou na coformação através do acompanhamento dos graduandos envolvidos com projetos nas escolas), identificamos o quanto os docentes que estão na EJA iniciam sua prática pedagógica sem conhecer as necessidades e características dessa modalidade, sem preparação especifica para atuar com esse público. Isso nos convoca a pensar sobre a responsabilidade das universidades diante dessa formação e, ainda, o quanto essa atuação nas escolas impacta a constituição dos próprios cursos de graduação e os formadores de professores.

A segunda consideração está relacionadaà produção acadêmica que envolve EF Escolar e EJA. Identificamos que a aproximação entre graduandos da área com essa modalidade da educação também significa contribuir para a construção de propostas curriculares e políticas de educação. Os direcionamentos por nós realizados dessa prática pedagógica no e com 0 conjunto da escola e das orientações que essas recebem, de forma crítica, dialogando com os contextos, criou possibilidades de novas composições no trato com a matéria - por meio de diferentes formas de produção acadêmica - as quais têm sinalizado para a necessidade de formação inicial para a modalidade, uma efetiva inserção na EJA, de modo a conhecer suas especificidades e desvelar os mecanismos perversos que têm levado à sua perpetuação. Quiçá, muitos(as) desses(as) professores(as), quando inseridos(as) nesse contexto que a modalidade requer, estarão em condições de exercer práticas pedagógicas sintonizadas com as necessidades e interesses do público da EJA, além de contribuir com novas produções.

Um terceiro destaque trata das singularidades das experiências por nós indagadas e relatadas. Sem dúvida, sistematizar o realizado, indagando-o e, ao mesmo tempo, compartilhando-o, nos trouxe efeitos, fazendo compor novos planejamentos e organizações - 
marca do pesquisar. Escrever este artigo e, ao mesmo tempo, conhecer mais a experiência realizada no Sul do Brasil, sua dinâmica, muito contribuiu na discussão do ajuste curricular do realizado na instituição do Sudeste, ecoando a demanda da área e da modalidade. Já a melhor compreensão da experiência realizada no Sudeste faz fortalecer o pertencimento na modalidade - algumas vezes abalada pelas dificuldades geradas pela incompreensão, em geral, da contribuição que a EF pode ter como prática pedagógica.

\section{CONSIDERAÇÕES FINAIS - E SEMPRE PROVISÓRIAS}

A síntese aqui apresentada expressa aproximações ainda iniciais, as quais nos cobram desdobramentos - por isso, será referência orientadora de futura ação conjunta, possivelmente no acompanhamento dos egressos.

Através dos projetos desenvolvidos nas unidades escolares e ouvindo os relatos dos professores nas ações de formações continuadas, conviver e identificar turmas com alto número de adolescentes possibilitou a desconstrução de uma leitura equivocada ou parcial da realidade. Inicialmente a grande presença de adolescentes nas turmas de EJA/ensino fundamental nos induz a pensar sobre as dificuldades ocorridas no percurso escolar ao longo da infância resultando no deslocamento desses adolescentes para a EJA. Nem sempre a questão de trabalho aparece em primeiro plano.

O que se desvelou para nós ao longo do tempo foi que, de um lado, existe um contingente de adolescentes que se transferem para a EJA por necessidade financeira da família, que os obriga a buscar trabalho em um período em que a os estudos ainda deveriam ser prioritários. De outra parte, observamos que muitos adolescentes, particularmente os meninos, relatavam que após sucessivas reprovações, os pais/responsáveis os obrigavam a trabalhar podendo continuar os estudos, mas no turno da noite. Tal situação revela um caráter punitivo acompanhado de discursos depreciativos em relação à capacidade de aprender desses sujeitos. Não é raro ouvir desses estudantes comentários negativos em relação a si mesmos, como: "Ah, eu sou burro mesmo, não aprendo" ou "Eu não dou para isso (estudo), não consigo". Há, portanto, um processo de juvenilização na EJA, que tem impactado nas aulas de EF, conforme problematizado por Franchi e Günther (2018).

Nossa intenção, ao pesquisar essas situações, é trazer à luz a complexidade do universo da EJA, as nuanças que marcam as histórias de vida de seus(uas) educandos(as) e a necessidade de exercitar um olhar sensível e atento para captar a inteireza desses sujeitos. Nesse movimento, para não ficar apenas na denúncia de uma realidade adversa para os alunos da EJA, mas favorecer que esses sujeitos tenham direito, pleno, de acesso e permanência na formação escolar, a qual possa anunciar práticas pedagógicas que partam e transcendam da realidade em que vivem, como nos indica Paulo Freire ${ }^{5}$ em diversas obras, torna-se fundamental que as universidades dialoguem com diferentes contextos sociais, práticas pedagógicas, profissionais, cotidianos escolares e cenários formadores de professores. Por isso, um trabalho colaborativo, como das autoras deste artigo, se faz presente e urgente.

Ao registrar e estudar o realizado, problematizamos e compartilhamos o que vem sendo realizado, na modalidade, pelos projetos que coordenamos em relação à formação 
inicial e continuada de professores para atuação na EJA. E, ao mesmo tempo, convidamos a olhar as experiências produzidas para a constituição da escolarização de adultos como uma tensão, constante, entre a regulação e a emancipação. Paiva (2005), ao indagar o que significa a educação de adultos na contemporaneidade, destaca que esse sentido é fruto do entrelaçamento de diferentes práticas nos espaços que educam (escolas, movimentos sociais, trabalho etc.) e que se organizam por meio de ordenações jurídicas, assim como por acordos firmados e aprovados nos cotidianos.

Como nós, professores(as) formadores(as) de novos(as) professores(as) - em tempos de novas Diretrizes Curriculares para a formação em EF; da Base Nacional Comum Curricular; do movimento Escola Sem Partido - cotidianamente nos organizamos para exercer a profissão?

Por tudo isso, pesquisamos e tornamos público o que realizamos.

\section{REFERÊNCIAS}

AMORIM, Antonio; DUQUES, Maria Luiza F. Formação de educadores de EJA: caminhos inovadores da prática docente. Educação, v. 40, n. 2, p. 228-239, maio/ago. 2017.

ARAÚJO, Matheus. A relação intergeracional na EJA. 2017. 33f. Trabalho de Conclusão de Curso (Graduação em Educação Física) - Universidade Federal Fluminense, Niterói, 2017.

ARENDT, Hannah. La crisis en la educación In: ARENDT, Hannah. Entre el pasado y el futuro: ocho ejercicios sobre la reflexión política. Barcelona: Península, 1996. p. 185 - 208.

ARROYO, Miguel. Outros sujeitos, outras pedagogias. Petrópolis: Vozes, 2012.

BARBIER, René. A pesquisa-ação. Brasília: Liber Livro, 2007.

BARBOSA-RINALDI, leda. Formação inicial em Educação Física: uma nova epistemologia da prática docente. Movimento, v. 14, n. 3, p. 185-207, set./dez. 2008.

BRASIL. Diretrizes Curriculares Nacionais para a EJA. Brasília: CNE/CEB, resolução no 1 de 2000. Disponível em: http://portal.mec.gov.br/cne/arquivos/pdf/pceb011_00.pdf Acesso em: 15 abr. 2018.

BRASIL. LDB: Lei de diretrizes e bases da educação nacional. 2. ed. Brasília, DF: Senado Federal, Coordenação de Edições Técnicas, 2018. 58 p. Disponível em: http://www2.senado.leg. br/bdsf/bitstream/handle/id/544283/lei de diretrizes e bases 2ed.pdf. Acesso em: 12 jul. 2018.

CARVALHO, Raphael. A prática da educação física na Educação de Jovens e Adultos. 2017. 47f. Trabalho de Conclusão de Curso (Graduação em Educação Física) - Universidade Federal Fluminense, Niterói, 2017a.

CARVALHO, Rosa Malena. A cultura corporal como concepção que organiza a educação física e caracteriza o escolar. Teias, v. 18, n. 49, p. 254-268, abr./jun. 2017b.

CARVALHO, Rosa Malena. A inclusão da educação física nos currículos: diálogo e formação com a EJA In: CARVALHO, Rosa Malena (org.). Docência na Educação de Jovens e Adultos (EJA) \& Educação Física. Curitiba: CRV, 2017c. p. 203-216. 
COSTA, Julio Cesar. Educação física escolar: promoção da saúde na Educação de Jovens e Adultos. 2014. 44f. Trabalho de Conclusão de Curso (Graduação em Educação Física) Universidade Federal Fluminense, Niterói, 2014p.

FRANCHI, Silvester; GÜNTHER, Maria Cecília Camargo. Juvenilização da EJA: repercussões na Educação Física. Motrivivência, v. 30, n. 53, p. 209-225, abr. 2018.

JARDILINO, José Rubens L. Educação de Jovens e Adultos: Sujeitos Saberes e Práticas. São Paulo: Cortez, 2014.

IBGE. Pesquisa Nacional por Amostra de Domicílios: síntese de indicadores 2014. Rio de Janeiro: IBGE, 2015. Disponível em: https://biblioteca.ibge.gov.br/visualizacao/livros/liv94935.pdf. Acesso em: 19 abr. 2019.

IBIAPINA, Ivana Maria L. Pesquisa colaborativa: investigação, formação e produção de conhecimento. Brasília: Líber Livro, 2008.

LAFFIN, Maria Hermínia L. F. A constituição da docência na Educação de Jovens e Adultos. Currículo sem Fronteiras, v.12, n.1, p. 210-228, jan./abr. 2012.

LARROSA, J. Herido de realidade y em busca de realidade. Notas sobre los lenguajes de la experiencia. In: CONTRERAS DOMINGO, José; FERRÉR, Nuria. (comps). Investigar la experiencia educativa. Madrid: Morata, 2010. p. 87-116.

MACHADO, Andréa. Os impactos e contribuições do Programa Institucional de Bolsa de Iniciação à Docência (PIBID) para a formação docente dos alunos/bolsistas egressos do curso de educação física da UFF. 2016. 66f Trabalho de Conclusão de Curso (Graduação em Educação Física) - Universidade Federal Fluminense, Niterói, 2016, 66pp.

MASSCHELEIN, Jan; SIMONS, Maarten. Em defesa da escola: uma questão pública. 2. ed. Belo Horizonte: Autêntica, 2014.

MELLO, Marco. Culturas e Identidades Juvenis: na EJA, de quem é mesmo o bagulho? Porto Alegre, 2009. Disponível em: http://websmed.portoalegre.rs.gov.br/escolas/emilio/autoria/ artigos2009/artigo-marco-2009.pdf .Acesso em: 20 jun.2018.

MINAYO, Maria Cecília. O Desafio do Conhecimento: pesquisa qualitativa em saúde. 14. ed. São Paulo: Hucitec, 2014.

PAIVA, Jane. Direito à educação de jovens e adultos: concepções e sentidos. In: REUNIÃO ANUAL DA ANPED, 29, 2005. Caxambu: 2005. http://29reuniao.anped.org.br/trabalhos/trabalho/ GT18-2553--Int.pdf. Acesso em: 5 mar. 2018.

SILVA, Gleice N.; GÜNTHER, Maria Cecília C. Formação de professores de educação física e a educação de jovens e adultos. In: CONGRESSO SULBRASILEIRO DE CIÊNCIAS DO ESPORTE, 17; CONGRESSO INTERNACIONAL DE CIÊNCIAS DO ESPORTE, 4, 2011, Porto Alegre. [Anais...]. Porto Alegre: CBCE, 2011. Disponível em: http://congressos.cbce.org.br/index. php/Conbrace2011/2011/schedConf/presentations. Acesso em: 05 fev.2018.

SILVA, Gleice. A formação inicial de professores de Educação Física e a educação de jovens e adultos. 2013.20f. Artigo de Conclusão de Curso (Especialização em Educação Física Escolar) - Universidade Federal de Santa Maria, Santa Maria, 2013. 
SOARES, Carmen Lúcia et al. Metodologia do Ensino da Educação Física. 2. ed. rev. São Paulo: Cortez, 2014.

SOARES, Leôncio. O educador de jovens e adultos e sua formação. Educação em Revista, $n$. 47, p. 83-100, jun. 2008.

SOARES, Leôncio. As especificidades na formação do educador de jovens e adultos: um estudo sobre propostas de EJA. Educação em Revista, v. 27, n.2, p. 303-322, ago. 2011.

SLOTERDIJK, Peter. Regras para o parque humano: uma resposta à carta de Heidegger sobre o humanismo. 3. ed. São Paulo: Estação Liberdade, 2000.

SOUZA JÚNIOR, Marcílio; TENÓRIO, Kadja; TAVARES, Marcelo; OLIVEIRA, Rodrigo; NEIRA, Marcos. Apropriações e produções curriculares de professores de Educação Física. Movimento, v. 23, n. 4., p. 1177-1190, out./dez. 2017.

TEIXEIRA, Ramon. Mídia e educação: a internet como uma ferramenta pedagógica para professores da Educação de Jovens e Adultos (EJA). 2013. 58f. Trabalho de Conclusão de Curso (Graduação em Educação Física) - Universidade Federal Fluminense, Niterói, 2013.

TROST, Gabriel. O processo de Juvenilização na Educação de Jovens e Adultos e as Aulas de Educação Física. 2015. 78f. Trabalho de Conclusão de Curso (Graduação em Educação Física) - Universidade Federal de Santa Maria, Santa Maria, 2015. 